\title{
Prototype of Hand Dryer with Ultraviolet Light Using ATMega8
}

\author{
Tatiya Padang Tunggal ${ }^{1}$, Ahmad Wahyu Apriandi ${ }^{2}$, Joessianto Eko Poetro ${ }^{3}$, Elsayed T. Helmy ${ }^{4}$, Farhad Waseel ${ }^{5}$ \\ ${ }^{1,2}$ Department of Electrical Engineering, Universitas Muhammadiyah Yogyakarta, Yogyakarta, Indonesia \\ ${ }^{3}$ Politeknik Perkapalan Negeri Surabaya, Surabaya, Indonesia \\ ${ }^{4}$ National Institute of oceanography and fisheries, Alexandria \\ ${ }^{5}$ Department of mathematics, Kabul University, Kabul, Afghanistan \\ Email: tatiyapt@umy.ac.id, ahmadwahyuapriandi@umy.ac.id, joessianto@ppns.ac.id, stalaat41@gmail.com,
} Farhadwaseel@ku.edu.af

\begin{abstract}
In everyday life, particularly in hospitals, people typically use cloth or tissue to dry our hands. It seems less practical, effective and hygienic. In addition, some restaurants still use cloth or tissue as well. To overcome this problem, several hospitals and restaurants have provided hand dryers. It can dry hands but cannot eliminate germs or bacteria. It is necessary to create a hand dryer equipped with a sterilizer. This work, therefore, created a hand dryer that can simultaneously dry and sterilize hands that worked automatically using the ATMega8 microcontroller. The tool was designed by using an infrared sensor to detect hands, and an ATMEGA8 microcontroller to read and process the sensors to activate $U V$ and heating. The results found that the tool equipped with $U V$ and heating can dry hands while eliminating bacteria and germs.
\end{abstract}

\section{Keywords - hand dryer, ultraviolet, microcontroller}

\section{INTRODUCTION}

People usually use cloth or towels to clean our hands. It's less practical, effective and hygienic. Hygiene is not maintained because the material is often contaminated with the hands of many other people. The hand towel gets dirty easily so that we often have to clean it. Because it is often washed away, it becomes brittle and easily damaged.

To overcome the problem, a hand dryer equipped with a temperature control was made. Some researchers have conducted studies controlling the temperature. Lin studied monitoring and control systems for smart plant growth environments. The system consisted of a photon flux density sensor, a microcontroller, and an actuator consisting of compressors, heaters, exhaust fans, and fluid heaters. [1]. Chen examined an intelligent temperature control system based on transcranial micro current depression therapy instrument. The system consisted of a temperature sensor using Pt100 which is inserted into the signal processor, an AT89S51 type microcontroller and a heater [2]. Mandala, Sumaryo, and Estananto investigated Nursery of smart golden fish eggs with a microcontroller. The system used four sensors consisting of temperature sensors using LM35, humidity sensors using ds18b20, proximity sensors using ultrasonic sensors and PH sensors. The sensor was processed using an Arduino mega2560 microcontroller [3].

Rego Segundo, Cocoa, and Ferreira developed an educational tool for control engineering. The tool consisted of a PIC18F4550 microcontroller, a mini cooler, a resistor, an
LM35 temperature sensor, a liquid crystal display, a USB connector, a transistor, an LED, a potentiometer, a resistor, and a capacitor [4]. Polyakov studied digital temperature meter polyethylene insulation. The system consists of ultraviolet radiation, temperature and humidity sensors, ATMEGA16 microcontroller [5]. Yingying studied control system for fresh air conditioning. The system consists of temperature and humidity sensors, microcontroller and air conditioners [6].

An automatic monitoring and control system within the greenhouse was investigated by Hassan. The system consisted of a light sensor, temperature and humidity sensors, an Arduino microcontroller, an exhaust fan, a water heater and a water pump [7]. Pawlenka and Skuta developed a microcontroller-based security system. The system consisted of three sensors consisting of gas sensors, humidity sensors and temperature sensors, an Arduino microcontroller and a web application [8]. LITA examined temperature control system for accelerated aging tests on printed circuit boards. The system consists of a temperature sensor, a heat sensor, a microcontroller PIC16F877, and the internet [9].

Sanjaya conducted research on smart quail incubators for hatching systems based on microcontrollers and the internet of things (IoT). The system consisted of temperature and humidity sensors, an Arduino microcontroller, lamp heaters and heaters [10]. Dhole and More studied embedded ethernet microcontroller prototype for monitoring and control different parameters. This system used two analog temperature channels, namely humidity sensor channel and optical sensor channel, connected with 8 light-emitting diodes to get high and low indications for each application simultaneously [11]. Ili Flores investigated simultaneous control of humidity and temperature logic in neonatal incubators. The sensor consisted of temperature and humidity sensors, an ARM cortex microcontroller, and a heater [12].

To solve these shortcomings and to be more practical, there are now several tools that can quickly dry hands called hand dryers. This hand drying method is commonly used in cafes, hotels, and hospitals. Essentially, the working principle of hand drying is drying with dry air blown away by a drying machine. The designed hand dryer machine uses infrared sensors and UV lamps. The addition of UV lamps can improve handwashing. The engine and UV lamp will work 
when the infrared sensor detects the presence of a hand (object) blocking it and stops working when the barrier is gone.

\section{METHOD}

The design of the block diagram of hand-taking with ultrasonic using a microcontroller according to Figure 1. From Figure 1, it appears that the system consists of sensors LM35 [3], [4], [13], [14], microcontroller [14]-[16], and driver to activate the UV lamp and dryer.

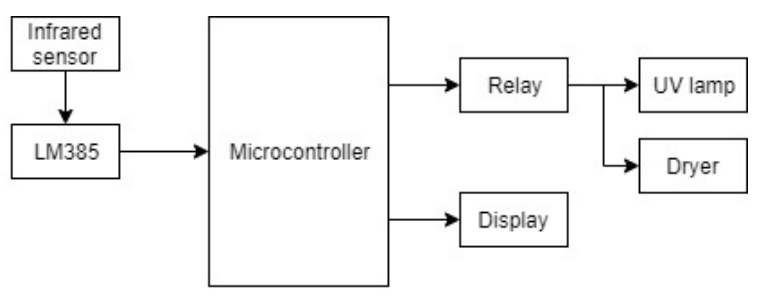

Fig. 1. System block diagram

The power supply was used to supply voltage to all circuits, and when the sensor detects the output [17]-[23] that is the object of the sensor in the form of a voltage, it is compared to the LM358 comparator [13], [24] and then executed by a microcontroller [25]-[27]. The microcontroller then instructs the relay to turn on the dryer and UV. Some will instruct the LCD [28]-[31] to display the word words before and after the object.

\section{A. System workflow program}

Figure 2 illustrates the system workflow diagram. It starts the process by pressing the power button to connect the power supply to the mains voltage. In the initialization step, the LCD will display the word WELCOME. When detecting a hand, the system is receiving data from an infrared sensor, but when no hand is detected, it returns to the previous step. When the sensor has detected a hand, the dryer and the UV light are on and the LCD will display DRYER \& UV ON. The drying time is 20 seconds. After 20 seconds, the dryer and the UV lamp lights off and the LCD will display DRYER \& UV OFF.

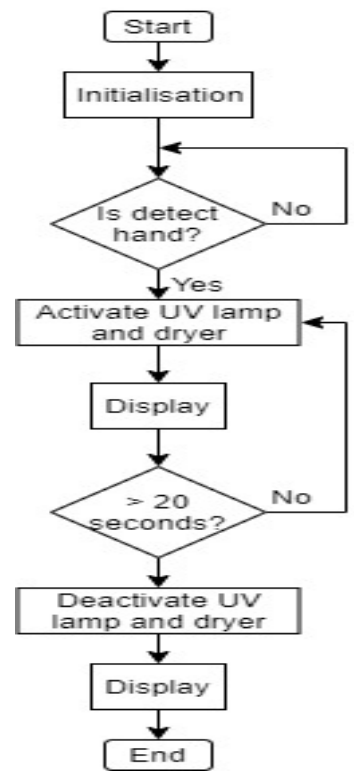

Fig. 2. System workflow diagram

\section{B. System hardware}

Figure 3 illustrates a front view image of the prototype hand dryer equipped with a UV lamp with an LCD display based on the ATmega 8 microcontroller. It consists of an LCD display, an infrared sensor, a UV lamp, and a dryer.

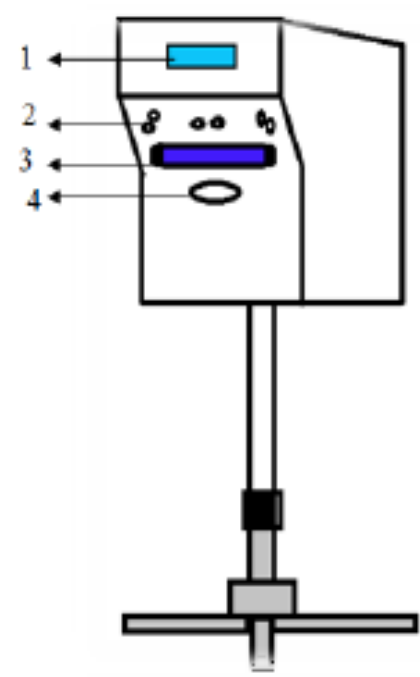

Fig. 3. Mechanical diagram

\section{RESULT AND DISCUSSION}

\section{A. Work of the system}

When the sensor has a voltage of $5 \mathrm{VDC}$, the infrared LED emits infrared light, and the photodiode is ready to receive the data. When the infrared LED is reflected because there are objects that reflect it, the photodiode receives data from the infrared. The output of this photodiode is a voltage that goes directly to the comparator circuit.

The output of the photodiode will be measured in the comparator circuit and then transmitted to the microcontroller in the form of binner numbers (0 and 1). When the microcontroller receives data 1 , the microcontroller will contact the relay to turn the UV lamp and dryer on for 20 seconds and change the display on the LCD, and when the microcontroller receives data 0 , the microcontroller will contact the relay to turn the UV lamp and dryer off.

\section{B. Infrared sensor test}

Figure 4 shows that the farther the distance of the hand placed in front of the infrared sensor, the smaller the output voltage from the infrared sensor, and the closer the hand is placed on the infrared sensor, the greater the output. The hand is ideally within $4-10 \mathrm{~cm}$ from the infrared sensor because at that distance, the output can still be received by the microcontroller. The lab test of the prototype hand dryer is equipped with a UV lamp with an LCD display based on ATMega8 microcontroller using E-Coli type bacteria conducted at the Microbiology Laboratory of the Faculty of Medicine and Health Sciences Universitas Muhammadiyah Yogyakarta using the method of counting the number of bacteria. From the above table it can be concluded that the distance of $10 \mathrm{~cm}$ with the use of tools for 20 seconds the EColi bacteria are not moving. 


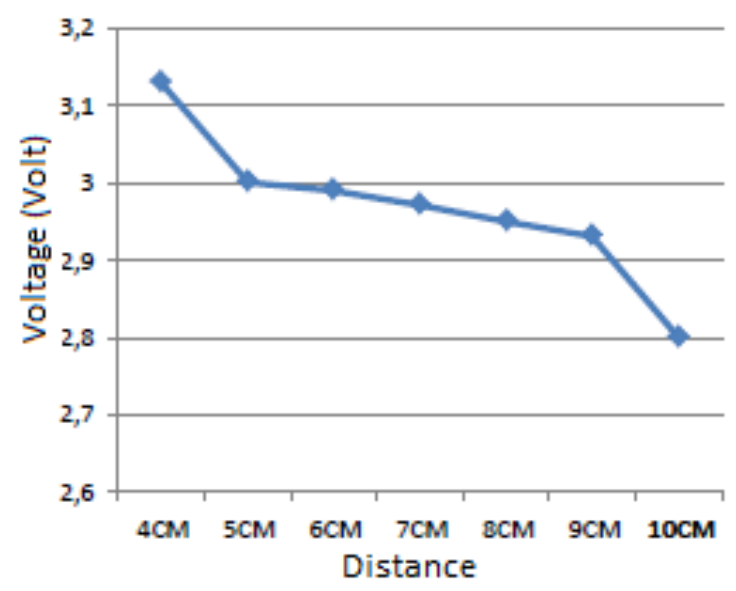

Fig. 4. The output response of the infrared sensor

Depending on the data retrieval of the defined range measurements, many different voltage readings are obtained. In 20 times experiments with a distance of $4 \mathrm{~cm}$, the average voltage obtained is 3.003 volts. Based on the data, the error value is 0.31 percent. At a distance of $10 \mathrm{~cm}$ in 20 times experiments, the average voltage obtained is 1.287 volts, so that the error value is $0.14 \%$. Depending on the data retrieval, the period of the hand dryer and UV lamps is 19.9 seconds on average so that the error is $0.5 \%$.

\section{CONCLUSIONS}

After carrying out the process of making, experimenting, testing tools, and data collection, the researcher may infer that the hand dryer and UV lamps would work on the basis of the sensory feedback. If the sensor detects the hands, the hand dryer and the UV lamp is on, and if the sensor does not detect the hands, the dryer and the UV lamp is off. The ideal distance of the hand from the infrared sensor is 1 to $10 \mathrm{~cm}$. The LCD displays a text when the dryer and UV are either on or off. It also displays a text when the dryer and UV lamp is working. The use of hand dryer tools with UV lamps is more hygienic in 20 times experiments with a distance of $4 \mathrm{~cm}$, the average voltage obtained is 3.003 volts. Based on the data, the error value is 0.31 percent. At a distance of $10 \mathrm{~cm}$ in 20 times experiments, the average voltage obtained is 1,287 volts, so that the error value is $0.14 \%$. Depending on the data retrieval, the period of the hand dryer and UV lamps is 19.9 seconds on average so that the error is $0.5 \%$.

\section{REFERENCES}

[1] H. Lin, M. Rui-Qi, C. Shi-Gang, Z. Yong-Li, and W. Xmg-Li, "Design of intelligent plant growth cabinet environment monitoring and control system," in 2018 Chinese Control And Decision Conference (CCDC), 2018, pp. 1472-1475.

[2] D. Chen et al., "Design of Temperature Intelligent Control System based on Transcranial Micro Current Depression Therapeutic Instrument," in 2018 IEEE International Conference on Mechatronics and Automation (ICMA), 2018, pp. 1345-1349.

[3] B. S. Mandala, S. Sumaryo, and Estananto, "Smart Gold Fish Eggs Nursery with Microcontroller," in 2018 International Symposium on Electronics and Smart Devices (ISESD), 2018, pp. 1-6.

[4] A. K. Rego Segundo, J. A. N. Cocota, and D. V. M. Ferreira, "Development of an educational tool for control engineering," in 2015 IEEE Global Engineering Education Conference (EDUCON), 2015, vol. 2015-April, no. March, pp. 594-601.
[5] D. A. Polyakov, D. A. Yurchuk, and K. I. Nikitin, "Digital temperature meter of polyethylene insulation," in 2015 International Siberian Conference on Control and Communications (SIBCON), 2015, pp. 1-4.

[6] C. Yingying, X. Xiuying, W. Ming, and J. Haiming, "Design of a control system for a fresh air conditioner," in The 27th Chinese Control and Decision Conference (2015 CCDC), 2015, pp. 56705675 .

[7] N. Hassan, S. I. Abdullah, A. S. Noor, and M. Alam, "An automatic monitoring and control system inside greenhouse," in 2015 3rd International Conference on Green Energy and Technology (ICGET), 2015, pp. 1-5.

[8] T. Pawlenka and J. Skuta, "Security system based on microcontrollers," in 2018 19th International Carpathian Control Conference (ICCC), 2018, pp. 344-347.

[9] A. I. LITA, D. A. VISAN, L. Mihai IONESCU, and A. G. MAZARE, "Temperature Control System for Accelerated Aging Tests on Printed Circuit Boards," in 2018 10th International Conference on Electronics, Computers and Artificial Intelligence (ECAI), 2018, pp. 1-4.

[10] W. S. M. Sanjaya et al., "The development of quail eggs smart incubator for hatching system based on microcontroller and Internet of Things (IoT)," in 2018 International Conference on Information and Communications Technology (ICOIACT), 2018, vol. 2018Janua, pp. 407-411.

[11] Y. P. Dhole and V. A. More, "Embedded Ethernet microcontroller prototype for different parameter monitoring and control," in 2015 International Conference on Energy Systems and Applications, 2015, no. Icesa, pp. 429-431.

[12] S. A. Ili Flores, H. J. Konno, A. M. Massafra, and L. Schiaffino, "Simultaneous Humidity and Temperature Fuzzy Logic Control in Neonatal Incubators," in 2018 Argentine Conference on Automatic Control (AADECA), 2018, pp. 1-6.

[13] Qurat.ul.Ain, M. Shah, M. Khan, and S. A. Mahmud, "Implementation of SCADA for multiple telemetry units while using GSM for communication," in 2015 International Conference on Emerging Technologies (ICET), 2015, pp. 1-4.

[14] P. Roy, J. Saha, N. Dutta, and S. Chandra, "Microcontroller based automated room light and fan controller," in 2018 Emerging Trends in Electronic Devices and Computational Techniques (EDCT), 2018, pp. 1-4.

[15] F. H. Purwanto, E. Utami, and E. Pramono, "Design of server room temperature and humidity control system using fuzzy logic based on microcontroller," in 2018 International Conference on Information and Communications Technology (ICOIACT), 2018, vol. 2018Janua, pp. 390-395.

[16] S. Bipasha Biswas and M. Tariq Iqbal, "Solar Water Pumping System Control Using a Low Cost ESP32 Microcontroller," in 2018 IEEE Canadian Conference on Electrical \& Computer Engineering (CCECE), 2018, vol. 2018-May, pp. 1-5.

[17] C. Cherciu, C. I. Cherciu, and D.-I. Nastac, "A portable device for intercepting and retransmission of infrared modulated signals," in 2015 IEEE 21st International Symposium for Design and Technology in Electronic Packaging (SIITME), 2015, pp. 277-280.

[18] B. Singh, "Armed anti infiltration robot based on peripheral interface controller using infrared ranging technique with single disc system," in 2014 International Conference on Computing for Sustainable Global Development (INDIACom), 2014, pp. 583-586.

[19] X. Han, "Infrared remote control design based on single chip microcomputer," in 2015 IEEE International Conference on Computer and Communications (ICCC), 2015, pp. 245-249.

[20] M. A. M. Fisol and W. M. Jubadi, "Ultrasonic and infrared repelling device for controlling the population of rat in paddy field," in 2010 IEEE Asia Pacific Conference on Circuits and Systems, 2010, pp. 359-361. 
[21] V. P. Rachim and W. Y. Chung, "Wearable-band type visible-near infrared optical biosensor for non-invasive blood glucose monitoring," Sensors Actuators, B Chem., vol. 286, no. January, pp. 173-180, 2019.

[22] R. A. De Lima and E. Fontana, "Single controller of DFB lasers for the simultaneous detection of multiple gases in the near infrared," SBMO/IEEE MTT-S Int. Microw. Optoelectron. Conf. Proc., vol. 2015-Decem, pp. 1-4, 2015.

[23] C. Pahl and E. Supriyanto, "Infrared based clinical landmark determination for ultrasound image acquisition," in 2015 38th International Conference on Telecommunications and Signal Processing (TSP), 2015, pp. 236-240.

[24] M. Noushad, B. Tauheed, S. A. Khan, and M. A. Khan, "Wireless monitoring of temperature and humidity using sensor array," in 2015 Annual IEEE India Conference (INDICON), 2015, pp. 1-5.

[25] D. F. G. Junco, D. F. Diaz Caro, M. S. C. Forero, and I. A. R. Ruge, "Agrometeorological monitoring station based microcontroller and bluetooth communication," in 2015 IEEE 2nd Colombian Conference on Automatic Control (CCAC), 2015, pp. 1-5.

[26] A. Mohini, "Microcontroller based orbital motion shaker," in 2015 International Conference on Intelligent Informatics and Biomedical Sciences (ICIIBMS), 2015, pp. 115-120.
[27] C. Rori, R. Munir, D. Paseru, and P. Manembu, "Fan temperature detection using microcontroller," in 2015 1st International Conference on Wireless and Telematics (ICWT), 2015, pp. 1-5.

[28] F. A. Kazan, H. Terzioglu, and A. C. Agacayak, "The Design of a Test \&amp;amp;amp; Development Board for the Training of PIC18F4550 Microcontroller," in 2015 2nd International Conference on Information Science and Control Engineering, 2015, pp. 951-955.

[29] V. P. Mohale, A. G. Hingmire, and D. G. Babar, "Ingenious energy monitoring, control and management of electrical supply," in 2015 International Conference on Energy Systems and Applications, 2015, no. Icesa, pp. 254-257.

[30] A. A. Aldair, A. T. Rashid, and M. Mokayef, "Design and Implementation of Intelligent Control System for Egg Incubator Based on IoT Technology," in 2018 4th International Conference on Electrical, Electronics and System Engineering (ICEESE), 2018, pp. 49-54.

[31] Chunli Jiang, Zhenglin Li, Yang Zhou, Xiaohu Qin, and Zeshuang Zhao, "Design of constant temperature boiler system with fuzzy control and remote monitoring function," in 2015 IEEE International Conference on Communication Problem-Solving (ICCP), 2015, pp. 38-42. 